\title{
An optimized staining technique for the detection of Gram positive and Gram negative bacteria within tissue
}

\author{
Sandra C. Becerra, Daniel C. Roy, Carlos J. Sanchez, Robert J. Christy and David M. Burmeister ${ }^{*}$
}

\begin{abstract}
Background: Bacterial infections are a common clinical problem in both acute and chronic wounds. With growing concerns over antibiotic resistance, treatment of bacterial infections should only occur after positive diagnosis. Currently, diagnosis is delayed due to lengthy culturing methods which may also fail to identify the presence of bacteria. While newer costly bacterial identification methods are being explored, a simple and inexpensive diagnostic tool would aid in immediate and accurate treatments for bacterial infections. Histologically, hematoxylin and eosin (H\&E) and Gram stains have been employed, but are far from optimal when analyzing tissue samples due to non-specific staining. The goal of the current study was to develop a modification of the Gram stain that enhances the contrast between bacteria and host tissue.
\end{abstract}

Findings: A modified Gram stain was developed and tested as an alternative to Gram stain that improves the contrast between Gram positive bacteria, Gram negative bacteria and host tissue. Initially, clinically relevant strains of Pseudomonas aeruginosa and Staphylococcus aureus were visualized in vitro and in biopsies of infected, porcine burns using routine Gram stain, and immunohistochemistry techniques involving bacterial strain-specific fluorescent antibodies as validation tools. H\&E and Gram stain of serial biopsy sections were then compared to a modification of the Gram stain incorporating a counterstain that highlights collagen found in tissue. The modified Gram stain clearly identified both Gram positive and Gram negative bacteria, and when compared to H\&E or Gram stain alone provided excellent contrast between bacteria and non-viable burn eschar. Moreover, when applied to surgical biopsies from patients that underwent burn debridement this technique was able to clearly detect bacterial morphology within host tissue.

Conclusions: We describe a modification of the Gram stain that provides improved contrast of Gram positive and Gram negative microorganisms within host tissue. The samples used in this study demonstrate that this staining technique has laboratory and clinical applicability. This modification only adds minutes to traditional Gram stain with reusable reagents, and results in a cost- and time-efficient technique for identifying bacteria in any clinical biopsy containing connective tissue.

Keywords: Staphylococcus aureus, Pseudomonas aeruginosa, Histology, Burn, Infection, Gram's stain

\section{Findings \\ Background}

In addition to metabolic functions of skin, the immune and protective capabilities of skin aid in separating the

\footnotetext{
${ }^{*}$ Correspondence: david.m.burmeister3.civ@mail.mil

Extremity Trauma and Regenerative Medicine Task Area, United States Army Institute of Surgical Research, 3650 Chambers Pass, JBSA Fort Sam Houston, TX 78234, USA
}

body's external and internal environments [1]. Cutaneous tissue is the first physical barrier preventing microbial invasion of underlying host tissues. When this barrier becomes compromised (e.g., after burn injury), bacteria have the opportunity to colonize tissues, subsequently leading to the development of infection. A large variety of different types of both acute (e.g., bites, scrapes) and chronic wounds (e.g., burns, diabetic foot ulcers) are 
susceptible to bacterial infection [2, 3]. Approximately $7-10 \%$ of all hospitalized patients are affected by skin and soft tissue infections [4]. Bacterial colonization of wounds inhibits and prolongs wound repair and complicates the clinical management of the patient [5]. Microorganisms can exist within wounds as either individual bacteria or as surface attached communities known as biofilms encased by a polymeric matrix composed of proteins, DNA and polysaccharides [6]. The state in which these microbes exist can have direct effects on diagnostic and treatment strategies.

Staphylococcus aureus and Pseudomonas aeruginosa, Gram positive and Gram negative microorganisms respectively, are two opportunistic pathogens that are among the most commonly associated with wounded tissue in patients $[7,8]$. Reports indicate that $S$. aureus and $P$. aeruginosa play a critical role in colonizing up to 93.5 and $52.2 \%$, respectively, of patients with chronic leg ulcers and burn infections [9]. Burn wounds are particularly susceptible to bacterial infections due to ease of access of nutrients for colonization [10]. Specifically, burns result in both loss of the epidermal layer and the formation of dead tissue known as an eschar. The denatured proteins and lipids in the burn eschar provides an advantageous environment for bacterial growth, and the resulting infection can spread systemically and impair the wound healing process $[11,12]$.

Rapid diagnosis of the presence of bacteria is essential for successful treatment of infected wounds, and clinical signs of infection have proven insufficient [13]. Identification of microbes through traditional culture-based techniques is limited and time consuming. Moreover, estimations are that only $\sim 10 \%$ of microorganisms can be successfully cultured in laboratory conditions, suggesting that culture alone is not sufficiently sensitive [14]. Therefore, a method to identify bacteria within infected wounds that is both reproducible and has a fast turnaround time, would aid in prompt and appropriate treatment. Given the limitations of traditional culturing, advanced techniques utilizing histological and molecularbased methods have proven useful [15-17]. While molecular methods such as in situ hybridization, RT-PCR (i.e., 16S rRNA sequencing) or FACS have proven more sensitive, they are associated with high costs and long acquisition times, as well as the potential for false positives (e.g., identifying non-viable bacteria) [18-20]. Histologically, specific antibodies (i.e., immunohistochemistry) allow for the detection of individual species of bacteria, including $S$. aureus and P. aeruginosa. While bacterial species can be identified in this way, these stains are also time consuming and expensive. Additionally, infections are often polymicrobial, and immunohistochemistry would fail to identify multiple organisms [7, 21-23].
Recent reports have advocated for the use of the hematoxylin and eosin (H\&E) stain over the Gram stain for detection of biofilms/bacteria in tissues [24, 25]. However, while existing patterns of inflammation elucidated via $H \& E$ can lead to some insight on the infection status of a wound, individual bacteria are not easily detected with H\&E staining alone [26]. Alternatively, the Gram stain is able to differentiate between Gram positive and Gram negative bacteria, and is the most used technique for classifying bacterial smears in vitro. However, within tissue sections, adaptations of this technique (e.g., Brown-Brenn staining, Goodpasture method, BrownHopps, Steiner and Steiner stain) are needed, which lead to preferential recognition of different organisms. These modifications take advantage of unique protein profiles within different bacteria, however proteins present in the host tissue are non-specifically stained in these Gram stain processes. Consequently, discerning bacteria becomes unfeasible, particularly in cases of burn wounds in which bacteria are present within a proteinrich eschar that retains non-specific dyes in both Gram and H\&E techniques [15]. In this study, we utilized a porcine burn model in which wounds were inoculated with either $S$. aureus or $P$. aeruginosa due to prevalence of these organisms in the clinic. Histological sections were taken to compare traditional histological stains (i.e., H\&E and Gram stain), to a new modification of the traditional Gram stain. Specifically, the modification employed a collagen counterstain during the dehydration process to contrast Gram positive or Gram negative bacterial colonies with collagen-containing tissue. Finally, we tested the applicability of this staining technique by performing it on clinical biopsies from patients that underwent burn debridement.

\section{Methods}

\section{Bacterial isolates and in vitro growth conditions}

A methicillin-resistant $S$. aureus clinical burn isolate was selected from strain USA300 at the US Army Institute of Surgical Research (JBSA Fort Sam Houston, TX, USA) collected as a part of patient care, but unrelated to research. P. aeruginosa strain PA01 is a well characterized wound isolate widely used as a laboratory strain [27-29]. S. aureus and $P$. aeruginosa were grown at $37^{\circ} \mathrm{C}$ on blood agar plates (Remel, Lenexa, KS), and single colonies from blood agar were then inoculated into cation-adjusted Muller Hinton broth (MHB II) (Becton-Dickinson, Franklin Lakes, NJ). Biofilms were prepared as described previously [30]. Briefly, mid-logarithmic culture grown bacteria $\left(\sim 10^{8} \mathrm{CFU} / \mathrm{mL}\right)$ were diluted 1:100 with MHB II. Subsequently, $250 \mu \mathrm{L}$ of the diluted bacteria was added to individual wells of a 24-well plate and incubated for $48 \mathrm{~h}$ at $37^{\circ} \mathrm{C}$ under static conditions. Following growth, 
biofilm bacteria were detached from the 24-well plates by combined washing with sterile PBS and mechanical disruption using a pipette. Bacterial smears were prepared by applying $50 \mu \mathrm{L}$ of the detached biofilms directly to slides followed by heat fixation.

\section{Tissue collection and processing}

This study has been conducted in compliance with the Animal Welfare Act, the Implementing Animal Welfare Regulations, and the principles of the Guide for the Care and Use of Laboratory Animals. Animal protocol A14-016 was approved by the Institutional Animal Care and Use Committee for United States Army Institute of Surgical Research. Skin biopsies from day 11 post-burn were kindly provided from a previously described porcine burn infected model currently under review [31]. Additionally, human samples of debrided burns were provided in a de-identified fashion by the United States Army Institute of Surgical Research Pathology Department. The use of human samples was approved by the institutional regulatory department. Both animal and human biopsies were fixed in $10 \%$ buffered formalin for at least $48 \mathrm{~h}$, and processed overnight in increasing amounts of ethanol, followed by three washes of xylene and subsequent equilibration in paraffin. Tissues were then embedded in paraffin blocks and cut into $6 \mu \mathrm{m}$ slices. Slides were deparaffinized, cleared in xylene, and rehydrated in preparation for staining.

\section{Staining techniques}

Antibody specificity for $S$. aureus and $P$. aeruginosa was tested in vitro by hydrating the biofilm or planktonic smears with Hank's balanced salt solution (HBSS). Smears were then blocked with $1 \%$ bovine serum albumin (BSA) in tris-buffered saline (TBS) with $0.1 \%$ Tween 20 and $0.1 \%$ Triton $\mathrm{X}-100$ for $1 \mathrm{~h}$ at room temperature. Smears were then incubated with the following primary antibodies for $1 \mathrm{~h}$ at room temperature: S. aureus-FITC (1:50 dilution in HBSS, ab68950, Abcam, Cambridge, UK), or P. aeruginosa (1:500 dilution in HBSS, ab74980, Abcam, Cambridge, UK). Following incubation, $P$. aeruginosa antibody was washed with HBSS and probed with a secondary antibody alexa-fluor 594 goat anti-chicken (1:500 dilution, ab150176, Abcam) for $1 \mathrm{~h}$ at room temperature. Both immunostains were completed with three washes in HBSS and subsequently mounted using ProLong Gold with 4',6-diamidino-2-phenylindole (DAPI; Life Technologies, Grand Island, NY). In addition to antibody specific staining, Gram stain was employed in vitro using standard protocol as described by the manufacturer (Remel, Lenexa, KS).

For staining of normal skin and infected burn biopsies ex vivo, serial tissue sections were obtained as described above. To verify the presence of $P$. aeruginosa and S. aureus, immunohistochemistry was performed on these sections identically to what is described above for in vitro smears. Additionally, sections were stained with H\&E (Sigma-Aldrich, St. Louis, MO) or Gram stain (Remel, Lenexa, KS). Gram stain was performed similarly to the smears described above with minor modifications (Fig. 1). Briefly, crystal violet was applied to the tissue sections for $5 \mathrm{~min}$ at room temperature, and slides were briefly rinsed under running tap water to remove excess crystal violet. Gram iodine mordant was applied for $2 \mathrm{~min}$ to the tissue sections and briefly washed in tap water. To remove any non-specific crystal violet staining, a Gram decolorizer solvent was applied to the slides for $30 \mathrm{~s}$ then quickly rinsed under running tap water until the water ran clear. The sections were then stained with

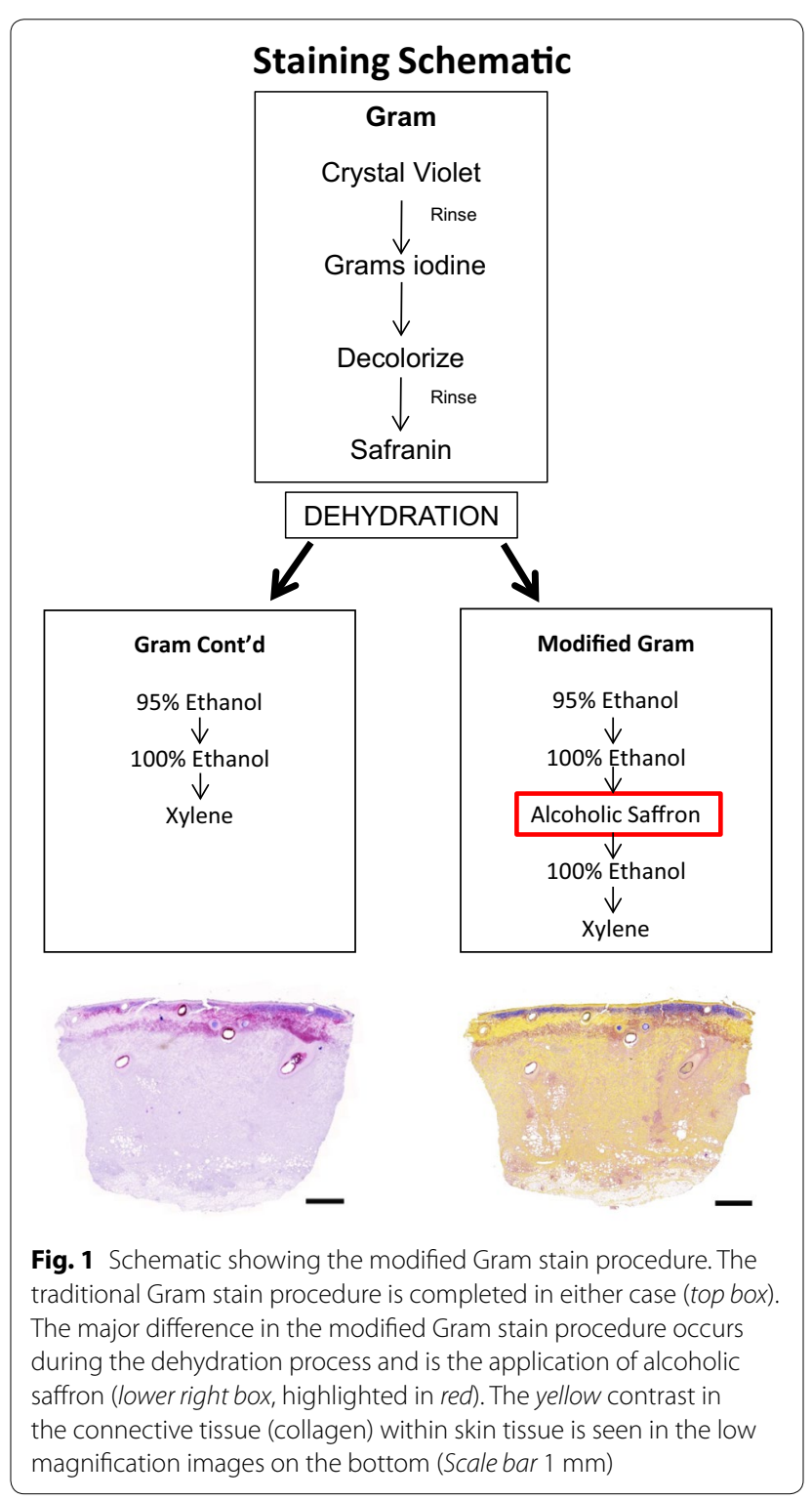


Gram Safranin for $1 \mathrm{~min}$ and $40 \mathrm{~s}$ and followed by dehydration through a series of alcohols (95-100 \%) to xylene and then coverslipped.

The modified Gram stain technique was performed in the same fashion as described in the Gram stain above, with the only addition of a counterstain after the first dehydration step of $100 \%$ alcohol (Fig. 1). At this point, slides were immersed in alcoholic saffron (American Master Tech Scientific, Inc., Lodi, CA) for $4 \mathrm{~min}$. After this incubation, the dehydration process was resumed by placing slides back into $100 \%$ ethanol, which also allowed for removal of excess alcoholic saffron, followed by a xylene wash and coverslipping.

\section{Microscopy}

Images of entire wound biopsies (both porcine and human) were obtained using an AxioScan Z1 slide scanner (Carl Zeiss, Inc., Thornwood, NY) at $10 \times$ magnification. Areas of interest from serial sections were imaged using an Olympus BX60 microscope equipped with a DP71 camera (Olympus Corporation, Tokyo, Japan). Brightfield images were taken, as were fluorescent images using $594 \mathrm{~nm}$ (P. aeruginosa), $488 \mathrm{~nm}$ (S. aureus) or $405 \mathrm{~nm}$ (DAPI) filters. High magnification images were obtained using a $100 \times$ objective under oil-immersion.

\section{Results and discussion}

Gram stain is the most common staining technique used diagnostically within both the clinical setting and in research laboratories to differentiate between Gram positive and Gram negative microorganisms in various types of tissues [17, 26]. As seen in Fig. 2, in vitro Gram stain of $S$. aureus and $P$. aeruginosa readily differentiates between these two classes of organisms in vitro. Moreover this distinction is still evident when applied to both large aggregates and individual detached bacteria within biofilms despite the presence of structures within the polymeric matrix such as carbohydrates, lipids and proteins that have the potential to interfere with the stain [32]. For a more detailed classification of the bacterial strains used in this study, antibodies specific for $S$. aureus or $P$. aeruginosa (i.e., immunocytochemistry) were used as a validation tool. As seen in Fig. 2c, d, the shape of bacilli and cocci bacteria are illustrated, demonstrating successful identification of $P$. aeruginosa strains and $S$. aureus, respectively.

Histologically, ex vivo detection of bacterial biofilms has been completed with expensive and time consuming techniques such as electron microscopy and confocal microscopy [33, 34]. Light microscopy has been pursued for biofilm localization in conditions such as rhinosinusitis [24, 25, 35]. However, in the case of burn wounds, non-specific staining of connective tissue, cellular debris, and other proteins present within the eschar occurs due to the absorption of the crystal violet dye used in the Gram stain [15]. Also, since the eschar provides essential nutrients that support bacterial growth, it is common to find colonizing bacteria at this site [11]. In this study, we employed a porcine model of infected burns to explore a modification of the traditional Gram stain that provides contrast with connective tissue to allow for better visualization of bacteria. Pigs are the ideal choice for studying skin wounds due to similarities to human skin. For example, pig skin and human skin are similar in their epidermal and dermal thicknesses, collagen content in both papillary and reticular dermal layers, distribution of hair follicles, and healing patterns (i.e., reepithelialization as opposed to contraction) [36, 37].

Initially, immunohistochemistry was performed with the previously verified antibodies to identify $P$. aeruginosa and $S$. aureus within burn wounds in this model (Fig. 3). Figure 3a, d show that these bacteria are not present within normal, non-burned pig skin. In Fig. 3b, we demonstrate that the $P$. aeruginosa specific antibody was able to detect $P$. aeruginosa within infected burn wounds, and are visualized as clusters of red bacilli within the superficial layers of the skin. Importantly, no reactivity of the $P$. aeruginosa antibody was seen in control pig skin, or in S. aureus infected samples (Fig. 3a, c). Similarly, the $S$. aureus antibody specifically labeled bacteria resent within $S$. aureus infected tissue visualized as green cocci (Fig. 3f), which was not seen in P. aeruginosa infected burns (Fig. 3c). Bacteria localization was also found to be different between the two species. P. aeruginosa localized more superficially on the burn eschar, generally an aerobic environment; whereas $S$. aureus was primarily located within/below the eschar, in a more anaerobic environment. Notably, this distribution of $S$. aureus and $P$. aeruginosa is consistent with earlier studies examining the invasiveness of these microorganisms in other models [38-41].

Despite the effectiveness of immunohistochemical techniques, the use of antibodies is time-consuming and expensive, and also requires prior knowledge of the bacterial species residing in the tissue of interest. Moreover, the majority of wound infections encountered are polymicrobial. Clinically, H\&E is the standard staining technique used by pathologists, and recently, has been used to identify bacteria in both planktonic and biofilm forms within wounds [24, 25]. H\&E staining has several attributes such as affordability and quick turnaround, as well as the ability to highlight both cells (hematoxylin) and connective tissue (eosin). However, retention of the dyes used in this stain can lead to misinterpreting clots and/ or eschar as bacteria within tissue sections. As seen in Fig. 4a, $H \& E$ is effective for highlighting tissue structure 


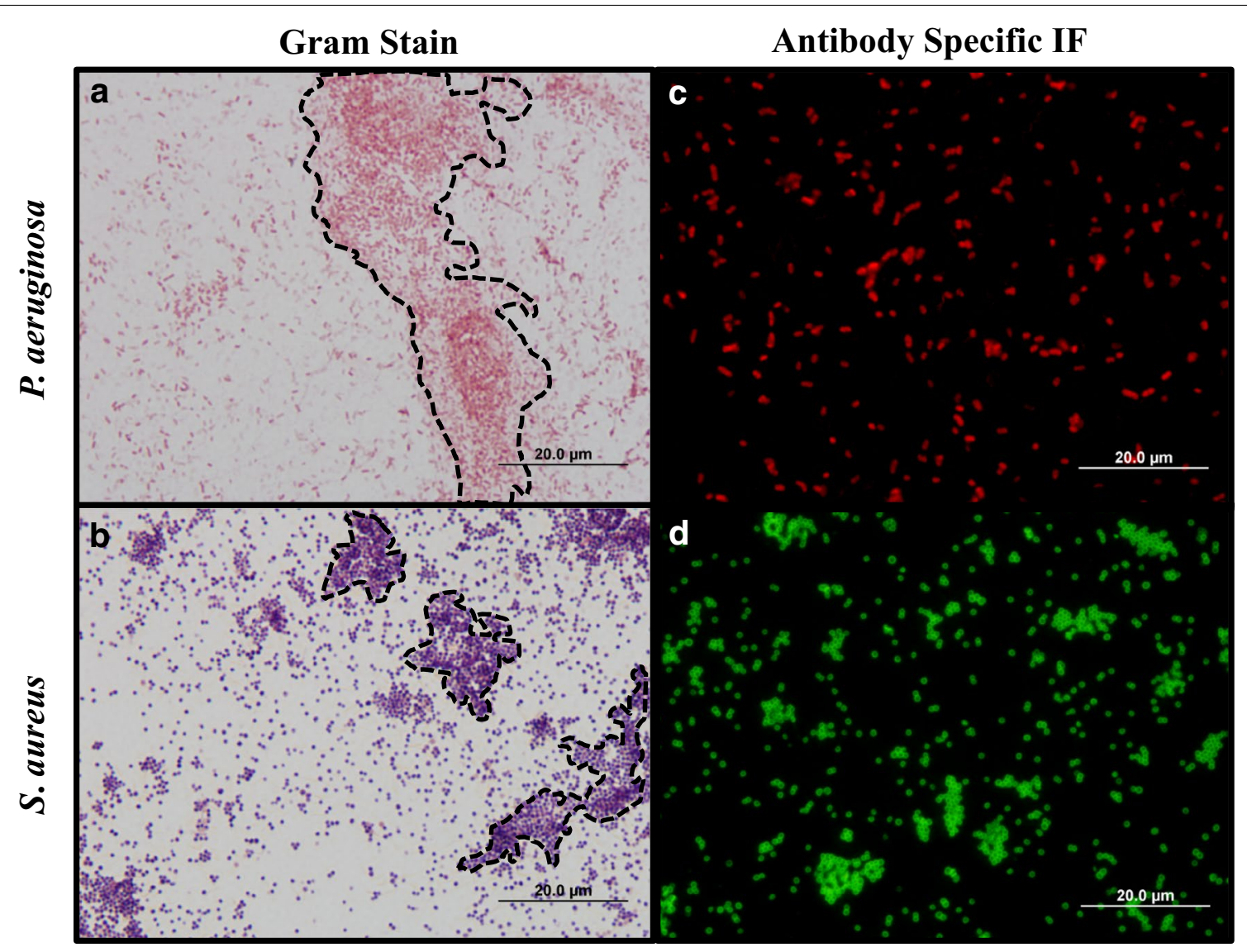

Fig. 2 In vitro validation of applied stains. Routine Gram stain shows identification of Gram negative (a P. aeruginosa) and Gram positive (b S. aureus) bacteria in both large aggregates (dotted lines) and individual bacteria within the biofilm. Selected P. aeruginosa (c) and S. aureus (d)-antibodies were used to confirm species identity of cultures used for ex vivo studies

and morphology in normal pig skin, with a superficial reticular dermis over the characteristic thicker fibers of the papillary dermis. After thermal injury H\&E is also effective in visualizing the coagulation of collagen within the eschar (Fig. 4b, c) as individual fibers are no longer apparent. Following infection with both $P$. aeruginosa (Fig. 4b) and S. aureus (Fig. 4c), H\&E becomes inadequate in clearly differentiating bacterial clusters from host cell debris and eschar components. This is, in part, due to the amount of dye retained within the tissue section non-specifically (i.e., the same areas of serial sections are darker after $H \& E$ sections versus the other stains). Furthermore, H\&E staining is not designed to distinguish Gram positive from Gram negative microorganisms. Based on these observations, interpretation of $\mathrm{H} \& \mathrm{E}$ staining in tissues can be subjective and lead to inconclusive, if not incorrect, diagnoses as to the presence or absence of bacteria.

The Gram stain has also been routinely used for in vitro and clinical samples alike, where cultures from patients are collected for bacterial identification [42]. Although
Gram stain is a fast, effective and inexpensive technique for bacterial differentiation, it does not allow for visualization of connective tissue (i.e., collagen) in histological samples. As seen in Fig. 4d, both cell components (e.g., nuclei) and collagen fibers are not apparent in normal pig skin. This is primarily attributed to the lack of counterstain (e.g., eosin dye in H\&E staining), in which a contrasting dye used for connective tissue would be valuable for structural information. The Gram stain is able to differentiate between Gram positive and Gram negative microorganisms ex vivo, as seen in Fig. 4e, f. However, non-specific staining of damaged tissue is also apparent, which can ultimately overestimate bacterial colonization in tissues. These observations lead us to conclude that although the Gram stain is the standard staining technique in vitro, its efficiency ex vivo can lead to subjective interpretation, and also fails to illustrate important aspects of tissue morphology (i.e., collagen).

Given the limitations of the two previously described stains we sought to develop an inexpensive and fast addition to the Gram stain that highlights tissue structure. 


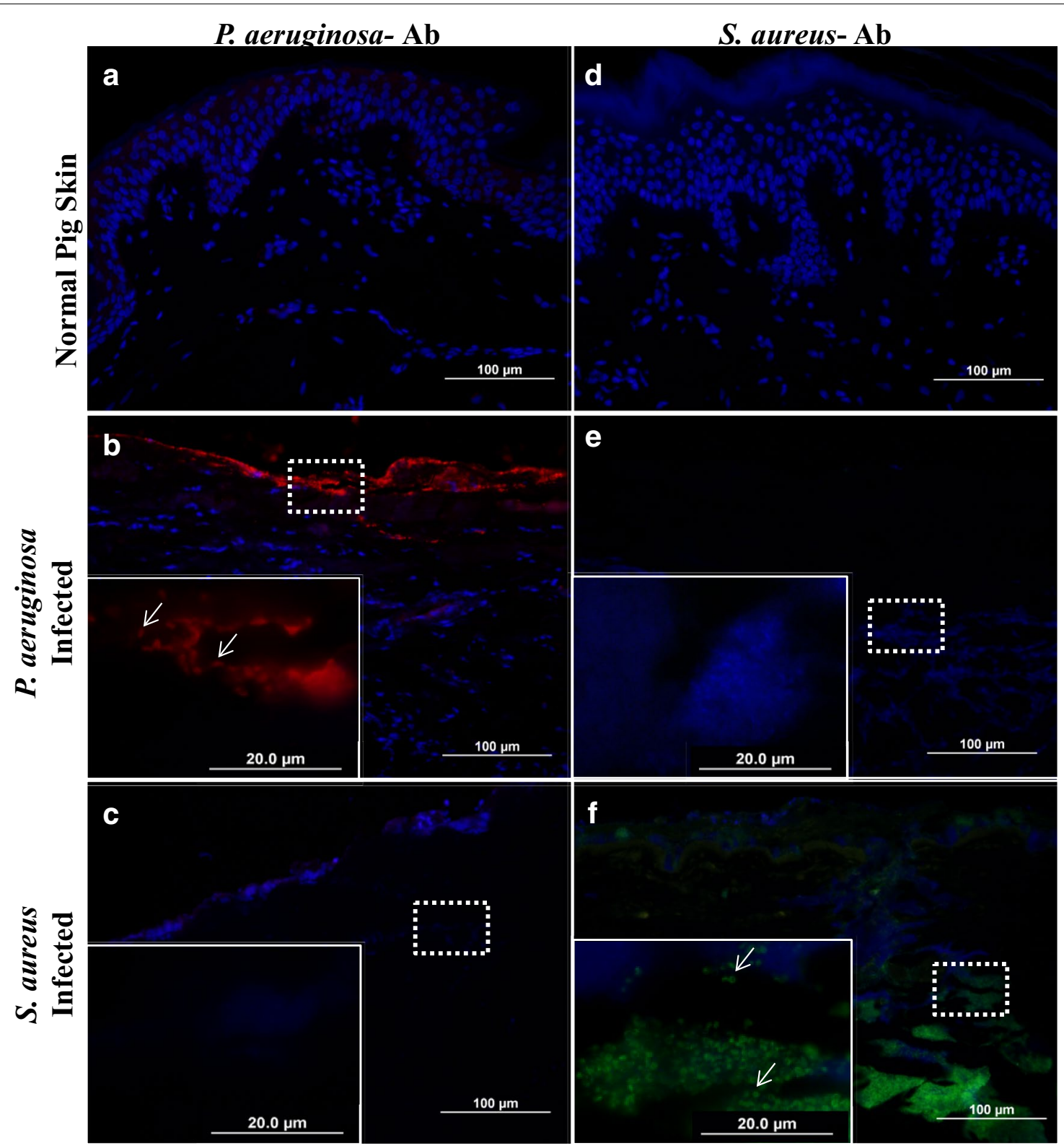

Fig. 3 Visualization of successful bacterial inoculation ex vivo. Normal pig skin $(\mathbf{a}, \mathbf{d})$, P. aeruginosa infected $(\mathbf{b}, \mathbf{e})$ and S. aureus infected (c, f) pig skin were subjected to immunohistochemistry with either P. aeruginosa $(\mathbf{a}-\mathbf{c})$ or S. aureus (d-f) antibodies. Note that these antibodies allow for specific labeling of bacteria ex vivo as indicated by arrows pointing out unique bacterial morphologies

To achieve this, we modified the Gram stain by incorporating alcoholic saffron as a contrasting dye. Although a similar stain has recently been reported by Roche et al., there was no description or optimization of the technique [43]. Alcoholic saffron has been traditionally used in other staining techniques (i.e., Movat's pentachrome) [44] for highlighting collagen fibers in tissue samples including burned skin [45]. As seen in Fig. 4g, collagen fibers within normal dermis are stained yellow with this solution, giving structural information not available following Gram stain alone. While collagen structure is greatly altered following burn injury as evidenced by coagulation seen in Fig. 4h, i, the alcoholic saffron retains the ability to dye the coagulated collagen. Importantly, this modification of the Gram stain retains the ability to distinguish both Gram positive (Fig. 4h) and Gram negative (Fig. 4i) microorganisms. The contrast provided by the alcoholic saffron allows bacteria to be detected deep within the burn eschar when compared to the Gram stain alone (Fig. 4h, e). Under low magnification, the 


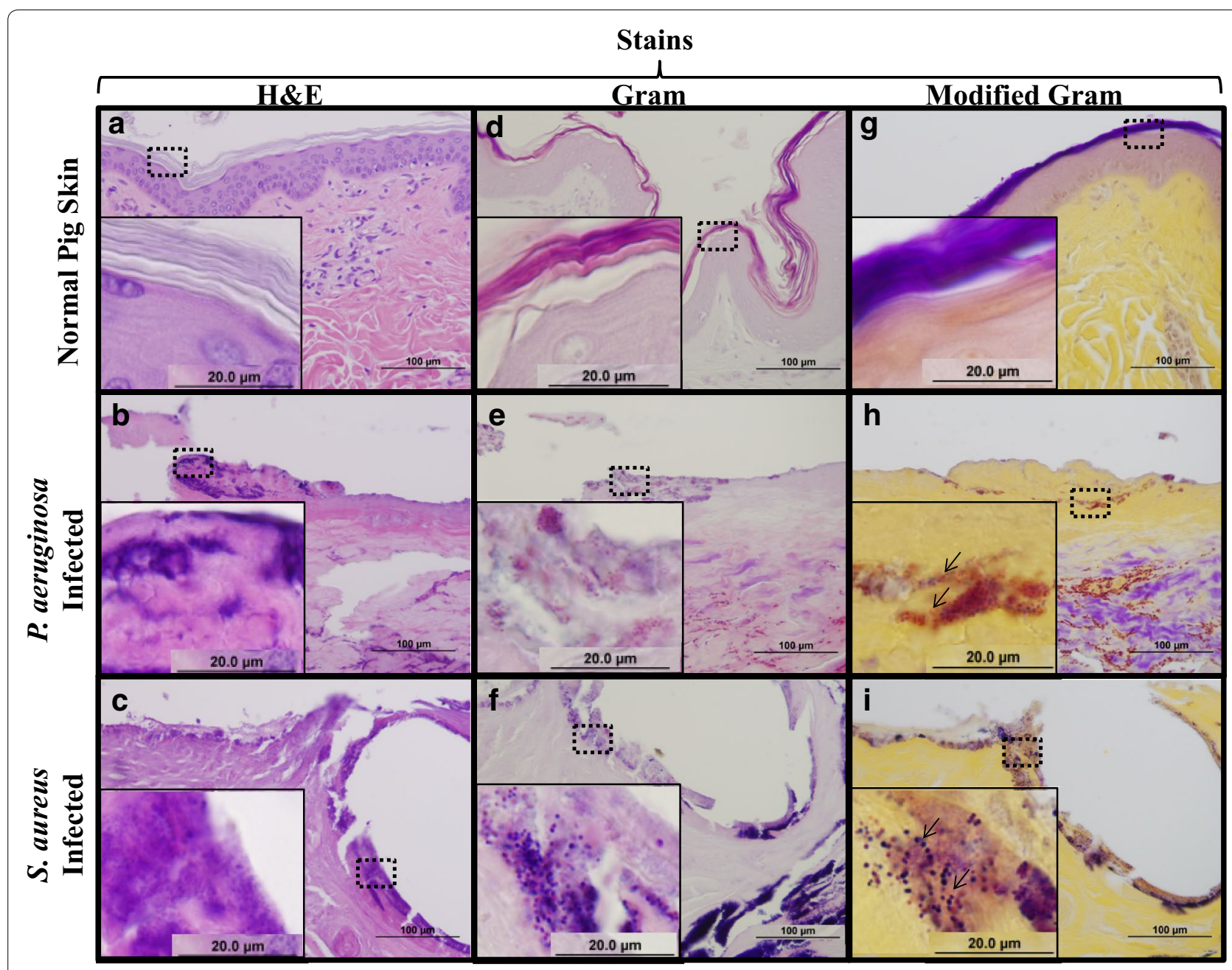

Fig. 4 A modified Gram stain improves bacterial detection in tissue sections. Serial sections of normal porcine skin (a, d, $\mathbf{g})$, P. aeruginosa infected $(\mathbf{b}, \mathbf{e}, \mathbf{h})$ or S. aureus infected $(\mathbf{c}, \mathbf{f}, \mathbf{i})$ burn wounds were stained with H\&E, Gram, and Modified Gram stain. H\&E of normal pig skin (a), P. aeruginosa infected (b) and S. aureus infected (c) pig skin illustrate coagulation of tissue, however staining within the burn eschar are not clearly identifiable as bacteria. Gram stain readily differentiates the clusters as Gram positive or Gram negative bacteria (e, $\mathbf{f})$, however there is lack of contrast in the tissue in all samples. This lack of contrast is alleviated in the modified Gram, stain which distinctly enhances the detection of bacterial clusters as Gram negative (h) or Gram positive (i)

modified Gram stain gives insight into the colonization of infected tissues by detecting differences in either red/ pink retained (P. aeruginosa) or deep violet (S. aureus). At high magnification, the morphology of the bacteria (i.e., cocci and bacilli) is also easily identified.

In order to test the clinical applicability of the modified Gram technique, the same staining comparison was performed on surgical biopsies from a de-identified patient (Fig. 5). The selection criteria for the biopsy were for a patient undergoing burn debridement, identified as having a polymicrobial infection. At low magnification, H\&E, Gram, and modified Gram (Fig. 5a, d, g, respectively) revealed a small amount of dermis overlaying a substantial amount of subcutaneous muscle. Higher magnifications of the $H \& E$ stain showed retention of Hematoxylin (purple) in both the skin (Fig. 5b) and muscle (Fig. 5c) areas without readily identifiable bacterial morphology. Of note, dye retention during the Gram stain process led to non-specific staining, especially in the skeletal muscle (Fig. 5f). This was slightly less apparent in the dermis (Fig. 5e), which allowed for bacteria visualization in areas of less dense host tissue. However, high magnification of the modified Gram stain clearly demonstrated bacterial morphology within dermal connective tissue (Fig. 5h) and subcutaneous muscle (Fig. 5i).

While a wide variety of molecular techniques (e.g., 16S rRNA pyrosequencing, in situ hybridization, RTPCR) are now available, it will take time before these 


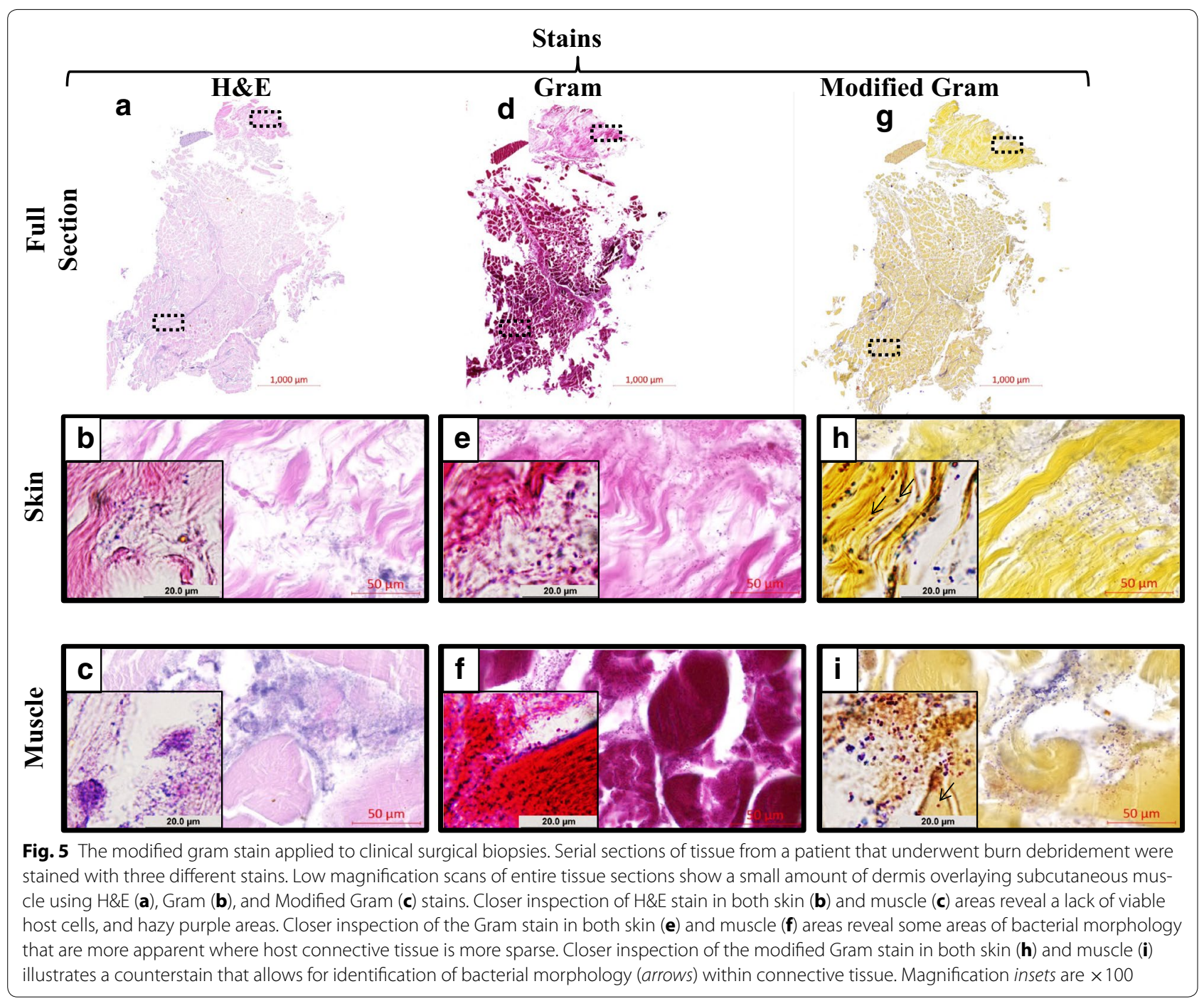

technologies may get sufficiently refined to allow for fast turn around and become clinically feasible. However, histopathology will always have a place for diagnosis of different tissues, and a quick, inexpensive, detailed, and reproducible histological technique for bacteria identification and localization is desired. The modified Gram stain we have described herein improves on the traditional Gram stain by providing contrast of connective tissues. The incubation time in alcoholic saffron for these tissues was found to be optimal at $4 \mathrm{~min}$. Less time led to lighter staining of the connective tissue, while longer incubation in alcohol began to remove the Gram stain components. This $4 \mathrm{~min}$ incubation represents a short addition to the staining process already in clinical use. While in this study we utilized paraffin embedding that takes several days of processing, a flash-freezing strategy could potentially allow for bacterial identification in less than an hour from biopsy collection [46].

There are potential limitations for implementing this stain. For example, certain species (e.g. fungi, acid fast bacteria, and other Gram variable bacteria) may not be highlighted using the Gram stain. However, the applications examined herein were aimed at addressing clinically relevant species of bacteria most often associated with wound infections. As such, these most common species present within chronic non-healing wounds would be detected with the technique described herein. Additionally, this staining technique does not provide any evidence for the species of bacteria present in tissue, which would need to be addressed with subsequent diagnostic tools. Also, tissues used in the current study have been optimized for infection which may make detection easier compared to a lesser amount of bacteria that may be 
present in an acute wound. Determining whether or not wounds that contain fewer bacteria would benefit from this stain is a point of further study.

\section{Conclusions}

We have described a histological technique that allows for visualization of tissue structures along with detection of Gram positive and Gram negative bacteria. An important advantage to the modified Gram stain is its ability to highlight collagen, making it applicable to any tissues that contain collagen. Employing this technique in other collagen-containing tissue samples may require optimization of staining times based on the collagen content of that tissue sample. As cutaneous tissue is very rich in dense collagen fibers, staining times may be even shorter for other tissues in which collagen is less abundant and/ or contained within certain locations (e.g., the lamina propria). We have demonstrated the clinical relevance of this modification to the Gram stain, in that it is capable of visualizing bacteria within burn wound samples from both the laboratory and the operating room. Moving forward this technique can be easily implemented in the clinic, allowing for rapid examination of the status of infection in tissue samples.

\section{Authors' contributions}

SB performed histological analysis and drafted the manuscript. DR participated in design of the study, animal surgeries and helped draft the manuscript. CS was involved in conception and design of the study and helped draft the manuscript. RC was involved in coordination of the study and helped draft the manuscript. DB organized the study design, was involved in conception and coordination of the study, and helped draft the manuscript. All authors read and approved the final manuscript.

\section{Acknowledgements}

The authors would like to thank the USAISR Veterinary Staff for their technical assistance, as well as MAJ Rose Grimm and Dr. Kathy Ryan for their assistance in procuring de-identified human samples. Medical Research and Materiel Command (MRMC) and Oak Ridge Institute for Science and Education (ORISE) provided funding for this project.

The opinions or assertions contained herein are the private views of the author and are not to be construed as official or as reflecting the views of the Department of the Army or the Department of Defense.

\section{Competing interests}

The authors declare that they have no competing interests.

Received: 9 October 2015 Accepted: 2 February 2016

Published online: 12 April 2016

\section{References}

1. Bangert C, Brunner PM, Stingl G. Immune functions of the skin. Clin Dermatol. 2011;29:360-76.

2. Costerton JW, Stewart PS, Greenberg EP. Bacterial biofilms: a common cause of persistent infections. Science. 1999;284:1318-22.

3. Hall-Stoodley L, Costerton JW, Stoodley P. Bacterial biofilms: from the natural environment to infectious diseases. Nat Rev Microbiol. 2004;2:95-108.
4. Ki V, Rotstein C. Bacterial skin and soft tissue infections in adults: a review of their epidemiology, pathogenesis, diagnosis, treatment and site of care. Can J Infect Dis Med Microbiol. 2008;19:173-84.

5. Swartz MN. Clinical practice. Cellulitis. N Engl J Med. 2004;350:904-12.

6. Bjarnsholt T. The role of bacterial biofilms in chronic infections. APMIS Suppl. 2013;136: 1-51

7. Dowd SE, Wolcott RD, Sun Y, McKeehan T, Smith E, Rhoads D. Polymicrobial nature of chronic diabetic foot ulcer biofilm infections determined using bacterial tag encoded FLX amplicon pyrosequencing (bTEFAP). PLoS One. 2008;3:e3326.

8. Wolcott RD, Gontcharova V, Sun Y, Dowd SE. Evaluation of the bacterial diversity among and within individual venous leg ulcers using bacterial tag-encoded FLX and titanium amplicon pyrosequencing and metagenomic approaches. BMC Microbiol. 2009;9:226.

9. Serra R, Grande R, Butrico L, Rossi A, Settimio UF, Caroleo B, Amato B, Gallelli $L$, de Franciscis S. Chronic wound infections: the role of Pseudomonas aeruginosa and Staphylococcus aureus. Expert Rev Anti Infect Ther. 2015;13:605-13.

10. Polavarapu N, Ogilvie MP, Panthaki ZJ. Microbiology of burn wound infections. J Craniofac Surg. 2008;19:899-902.

11. Gurfinkel R, Rosenberg L, Cohen S, Cohen A, Barezovsky A, Cagnano E, Singer AJ. Histological assessment of tangentially excised burn eschars. Can J Plastic Surg. 2010;18:e33-6.

12. Sevgi M, Toklu A, Vecchio D, Hamblin MR. Topical antimicrobials for burn infections: an update. Recent Pat Anti Infect Drug Discov. 2013;8:161-97.

13. Gardner SE, Frantz RA, Doebbeling BN. The validity of the clinical signs and symptoms used to identify localized chronic wound infection. Wound Repair Regen. 2001;9:178-86.

14. Grice EA. The skin microbiome: potential for novel diagnostic and therapeutic approaches to cutaneous disease. Semin Cutan Med Surg. 2014;33:98-103.

15. Church D, Elsayed S, Reid O, Winston B, Lindsay R. Burn wound infections. Clin Microbiol Rev. 2006;19:403-34.

16. Misic AM, Gardner SE, Grice EA. The wound microbiome: modern approaches to examining the role of microorganisms in impaired chronic wound healing. Adv Wound Care. 2014;3:502-10.

17. Baron EJ, Miller JM, Weinstein MP, Richter SS, Gilligan PH, Thomson RB Jr, Bourbeau P, Carroll KC, Kehl SC, Dunne WM, et al. A guide to utilization of the microbiology laboratory for diagnosis of infectious diseases: 2013 recommendations by the Infectious Diseases Society of America (IDSA) and the American Society for Microbiology (ASM). Clinical Infect Dis. 2013;57:e22-121.

18. Choi YS, Kim YC, Baek KJ, Choi Y. In situ detection of bacteria within paraffin-embedded tissues using a digoxin-labeled DNA probe targeting 16S rRNA. J Vis Exp. 2015;(99):e52836.

19. Enomoto H, Inoue S, Matsuhisa A, Nishiguchi S. Diagnosis of spontaneous bacterial peritonitis and an in situ hybridization approach to detect an "unidentified" pathogen. Int J Hepatol. 2014;2014:634617.

20. Yan W, Xing Y, Yuan LC, De Yang R, Tan FY, Zhang Y, Li HY. Application of RLEP real-time PCR for detection of $M$. leprae DNA in paraffin-embedded skin biopsy specimens for diagnosis of paucibacillary leprosy. Am J Trop Med Hyg. 2014;90:524-9.

21. Dowd SE, Delton Hanson J, Rees E, Wolcott RD, Zischau AM, Sun Y, White J, Smith DM, Kennedy J, Jones CE. Survey of fungi and yeast in polymicrobial infections in chronic wounds. J Wound Care. 2011;20:40-7.

22. Rhoads DD, Cox SB, Rees EJ, Sun Y, Wolcott RD. Clinical identification of bacteria in human chronic wound infections: culturing versus 165 ribosomal DNA sequencing. BMC Infect Dis. 2012;12:321.

23. Wolcott R, Costerton JW, Raoult $D$, Cutler SJ. The polymicrobial nature of biofilm infection. Clin Microbiol Infect. 2013;19:107-12.

24. Hochstim CJ, Choi JY, Lowe D, Masood R, Rice DH. Biofilm detection with hematoxylin-eosin staining. Arch Otolaryngol Head Neck Surg. 2010;136:453-6.

25. Hong SD, Dhong HJ, Chung SK, Kim HY, Park J, Ha SY. Hematoxylin and eosin staining for detecting biofilms: practical and cost-effective methods for predicting worse outcomes after endoscopic sinus surgery. Clin Exp Otorhinolaryngol. 2014;7:193-7.

26. Woods GL, Walker DH. Detection of infection or infectious agents by use of cytologic and histologic stains. Clin Microbiol Rev. 1996;9:382-404.

27. Holloway BW. Genetic recombination in Pseudomonas aeruginosa. J Gen Microbiol. 1955:13:572-81. 
28. Schmidt KD, Tummler B, Romling U. Comparative genome mapping of Pseudomonas aeruginosa PAO with $P$. aeruginosa $C$, which belongs to a major clone in cystic fibrosis patients and aquatic habitats. J Bacteriol. 1996;178:85-93.

29. Mittal R, Grati M, Gerring R, Blackwelder P, Yan D, Li JD, Liu XZ. In vitro interaction of Pseudomonas aeruginosa with human middle ear epithelial cells. PLoS One. 2014;9:e91885.

30. Cardile AP, Sanchez CJ Jr, Samberg ME, Romano DR, Hardy SK, Wenke JC, Murray CK, Akers KS. Human plasma enhances the expression of Staphylococcal microbial surface components recognizing adhesive matrix molecules promoting biofilm formation and increases antimicrobial tolerance in vitro. BMC Res Notes. 2014;7:457.

31. Roy DC, Tomblyn S, Isaac KM, Kowalczewski CJ, Burmeister DM, Burnett LR, Christy RJ. Ciprofloxacin-loaded keratin hydrogels reduce infection and support healing in a porcine partial-thickness thermal burn. Wound Repair Regen. 2016 (In Press).

32. Mann EE, Wozniak DJ. Pseudomonas biofilm matrix composition and niche biology. FEMS Microbiol Rev. 2012;36:893-916.

33. Mladina R, Poje G, Vukovic K, Ristic M, Music S. Biofilm in nasal polyps. Rhinology. 2008;46:302-7.

34. Psaltis AJ, Ha KR, Beule AG, Tan LW, Wormald PJ. Confocal scanning laser microscopy evidence of biofilms in patients with chronic rhinosinusitis. Laryngoscope. 2007;117:1302-6.

35. Toth L, Csomor P, Sziklai I, Karosi T. Biofilm detection in chronic rhinosinusitis by combined application of hematoxylin-eosin and gram staining Eur Arch Otorhinolaryngol. 2011;268:1455-62.

36. Singer AJ, McClain SA. A porcine burn model. Methods Mol Med. 2003;78:107-19.

37. Sullivan TP, Eaglstein WH, Davis SC, Mertz P. The pig as a model for human wound healing. Wound Repair Regen. 2001;9:66-76.
38. Malic S, Hill KE, Hayes A, Percival SL, Thomas DW, Williams DW. Detection and identification of specific bacteria in wound biofilms using peptide nucleic acid fluorescent in situ hybridization (PNA FISH). Microbiology. 2009;155:2603-11.

39. Pastar I, Nusbaum AG, Gil J, Patel SB, Chen J, Valdes J, Stojadinovic O, Plano LR, Tomic-Canic M, Davis SC. Interactions of methicillin resistant Staphylococcus aureus USA300 and Pseudomonas aeruginosa in polymicrobial wound infection. PLoS One. 2013;8:e56846.

40. Seth AK, Geringer MR, Galiano RD, Leung KP, Mustoe TA, Hong SJ. Quantitative comparison and analysis of species-specific wound biofilm virulence using an in vivo, rabbit-ear model. J Am Coll Surg. 2012;215:388-99.

41. Seth AK, Geringer MR, Hong SJ, Leung KP, Galiano RD, Mustoe TA. Comparative analysis of single-species and polybacterial wound biofilms using a quantitative, in vivo, rabbit ear model. PLoS One. 2012;7:e42897.

42. Elgharably H, Mann E, Awad H, Ganesh K, Ghatak PD, Gordillo G, SaiSudhakar CB, Roy S, Wozniak DJ, Sen CK. First evidence of sternal wound biofilm following cardiac surgery. PLoS One. 2013;8:e70360.

43. Roche ED, Renick PJ, Tetens SP, Carson DL. A model for evaluating topical antimicrobial efficacy against methicillin-resistant Staphylococcus aureus biofilms in superficial murine wounds. Antimicrob Agents Chemother. 2012;56:4508-10.

44. Movat HZ. Demonstration of all connective tissue elements in a single section; pentachrome stains. AMA Arch Pathol. 1955;60:289-95.

45. Hirth DA, Singer AJ, Clark RA, McClain SA. Histopathologic staining of low temperature cutaneous burns: comparing biomarkers of epithelial and vascular injury reveals utility of HMGB1 and hematoxylin phloxine saffron. Wound Repair and Regen. 2012;20:918-27.

46. Burry RW. Tissue sectioning. In: Immunocytochemistry. New York: Springer; 2010. p. 29-44

\section{Submit your next manuscript to BioMed Central and we will help you at every step:}

- We accept pre-submission inquiries

- Our selector tool helps you to find the most relevant journal

- We provide round the clock customer support

- Convenient online submission

- Thorough peer review

- Inclusion in PubMed and all major indexing services

- Maximum visibility for your research

Submit your manuscript at www.biomedcentral.com/submit

C Biomed Central 